\title{
Best Practices for Leading Technology Change in Large Scale School Systems
}

\author{
Monica Depta \\ Ontario Institute for Studies in Education, University of Toronto, Canada
}

\begin{abstract}
This is a study of a specific school board's experience with the transformation to 21 st century learning and teaching via technology implementations at the school level. The study looks at successful technology implementations by analyzing interview data from school board administrators and superintendents involved in several effective school implementations. In essence, what practices and underlying philosophies are adopted by school board leadership and school administrators in the successful technology implementations in K-12 schools? The paper builds upon United States based research by examining excellence in technology implementations in schools in Canada. The implications for practice are applicable to all education organizations to create awareness of factors needed for school level change to occur.
\end{abstract}

\section{Introduction}

What is it that makes some schools more successful with implementation of technology than others? In theory, the same vision and values are established in an education organization, such as a school board. However, the outcome of projects, programs and policies often differ.

How do school board administration and superintendents implement these changes, particularly in schools that are leaders in adoption of technology in their classrooms? How do these administrators and education leaders facilitate an adoption of change? What techniques of leadership do they use? How do their actions correspond to comparable research findings?

In order to narrow the focus to a more measurable and currently relevant example, I will study the technology implementations at a single school board. The focus will be on examples of excellence in schools that have implemented technology successfully. Through qualitative, interview-based research, I will be using the findings of recent research studies of technology implementations in a K-12 setting in order learn more about the philosophies, practices and elements of successful technology implementation. The interviews will build on research findings from comparable studies conducted in United States based schools, in order to expand on the findings and validate them in the Canadian context. The core question in this study is, what practices and

underlying philosophies are adopted by school board leadership and school administrators in the successful implementations of technology-based, 21st Century learning and teaching programs and policies?

\section{Literature Review}

Barbara Levin and Lynne Schrum published a similar study, based in the United States "Using Systems Thinking to Leverage Technology for School Improvement: Lessons Learned from AwardWinning Secondary Schools/Districts". This study concluded that eight particular factors are required for successful school district technology implementation:

1. Vision

2. Distributed Leadership

3. School Culture

4. Technology Planning, Infrastructure and Support

5. Professional Development

6. Curriculum and Instructional Practices

7. Funding

8. Partnerships [18].

Levin and Schrum's study sparked my interest to find out more about the eight factors they listed as required in school district technology implementations.

I turned to more research studies on the subject of technology implementations in K-12 context. It turns out various studies, which observed the changes in education due to the infusion of technology, named similar factors of success required to conduct these types of changes in schools. Liu and Szabo [19], for example, examined teachers' attitudes toward technology integration in schools over four years. They observed five "interventions at the school or district level for improving teachers' technology integration":

1. Instructional resources

2. Technical infrastructure

3. Professional development

4. Leadership type in schools and Guidance. [19].

Another study outlining issues with preparing teachers for ICT-TPCK (Information and communication technologies - technological 
pedagogical content knowledge) states: "The preparation of teachers in the educational uses of technology appears to be a key component in almost every improvement plan for education reform efforts", thus suggesting professional development for teachers is a key factor [1]. Yet another study by Kopcha [17] presents a systems-based mentoring model of technology integration, which includes the following factors:

1. Needs assessment

2. Vision and goals

3. Planning for technology infrastructure

4. Planning for teacher preparation

5. Curriculum focus

6. Establishing communities of practice [17].

Overall, research on the subject of technology integration in schools indicates that there are key components that need to be present to successfully implement technology in classrooms. These components always include professional development and often indicate leadership, vision, technology infrastructure, curriculum and instructional practice and school culture.

\section{Conceptual and theoretical frameworks}

This study leverages the concepts of Activity and Systems Theories. Activity theory is particularly well paired with qualitative research. Activity theory is applied during the construction of the interview questions and the interviewing process. An Activity theory lens enables to identify what actions and interactions take place during an implementation of particular technology related initiatives. Systems Theory, on the other hand, is the lens utilized to draw patterns that enables conclusions and leads to concrete factors of success that can be used in practice going forward.

\subsection{Contribution}

I hope this research paper can be used as a reference for school boards, superintendents, principals and schools in the adoption of change. This research will be based on Levin and Schrum's success factors to guide school board leadership in inclusion of key components of technology implementations. Successful program implementations lead to less anxiety in the workplace and enable the teaching staff to continue being facilitators of students' success, without the turbulence that unsuccessful implementations can create.

I strongly believe in technology being a positive influence for student learning. Herrington and Kervin [43] validate this belief in their study "Authentic learning supported by technology: Ten suggestions and cases of integration in classrooms."
In this study they concluded that technology enhances the education experience for students and that students benefit from technology as part of instruction because the experience the learning provided, in comparison to teacher delivered factbased instruction [43].

\subsection{Research Methods}

This is a qualitative research study. Because of the unique nature of schools and school boards, qualitative study allows a detailed level of questioning and understanding of each school environment described in the interviews.

The interviews refer to specific projects as part of the overall program implementation for the $21^{\text {st }}$ century learning and teaching vision. This is designed to help the interviewees to focus on specific examples and recall their actions associated with particular implementations. A qualitative approach, conducted via face-to-face individual semi-structured interviews allows a descriptive conversation, which reveals the participants' change management practices and how they applied them in successful technology implementations.

\subsection{Data collection: Semi structured interviews}

Semi structured face-to-face interviews were conducted. Although expected to last approximately 60 minutes, most ended up being well over and even into 2-3 hours. The questions were built upon the eight success factors identified by Levin and Schrum in their analysis of successful school technology implementations [18]. Participants were stakeholders who played a key role in successful technology implementations at a particular school board.

\section{Interviewees}

A total of nine interviews were conducted. Two participants were able to provide input based on two different roles they occupied during the timing relevant to this research. Their perspective brings the total participant input to the following group:

- Communication and Community Relations Department management representation

- Curriculum and Instruction Department Head

- Instructional Teaching Coordinator

- two IT Managers

- Principal

- School Support Officer - Policy

- four Superintendents of Education 


\section{Strategy}

The school board began its mission to transform education as we know it by equipping its schools with the technical infrastructure required to carry out its learning and teaching vision. Superintendents and senior leaders were dispatched to various Canadian and American school boards to research what others were doing to advance education methods. The senior team also started reading and listening to various individuals who were emerging as spokespeople for this new educational movement [15]. Leaders such as Michael Fullan, Will Richardson or George Couros became a conduit to various ideas which were then turned into the strategy for change of education at this particular board [8], [9], [12], [13], [15], [16]. An internal report on the current state of culture, cohesion and a measure of how staff and leaders in the school board perceived these required changes was conducted by third party experts in the field of education change. The report's findings validated some reasons for an adjustment in strategy to create change [12] - [15].

The various tactics described by the interviewees, which comprised the change strategy were $^{1}$ :

- Adopting a co-learning stance. Collaborative enquiry happens when teams of educators, such as principals, teachers, superintendents, school board leaders come together to discuss student learning [12]- [13], [15]

- Adoption of SAMR model. Helped to validate that substitution is a natural first step in progress [8]- [13], [15]- [16]

- Increasing Support Staff. Technology (IT) resource teachers were added to provide the system with adequate support [8], [10]- [12], [14]- [15]

- Establish a culture of YES. Superintendents and Principals began to encourage risk taking and trying of new techniques in classrooms [8][10], [12]- [16]

- Superintendent role shifts to Educational and Innovation Leaders. Enabling the Superintendents of Education to be educational leaders. Superintendents were traditionally considered to be managers rather than instructional leaders. Superintendents immersed themselves individually and as a group in knowledge seeking and bringing out ideas to experiment with [9], [12], [14]- [15]

- Not implementing from the top but bottom up. This board ensured that the focus was on grass roots messaging and movements, rather than being the leader of all changes [8]- [10], [12]- [16]

\footnotetext{
${ }^{1}$ The initiatives listed are not named exactly how the board internally labelled them.
}

- Digital Citizenship. Digital Citizenship refers to the release of character attributes that define the school board and the Digital Citizenship Policy. This initiative was released by the Board early on in their journey towards the adoption of technology. The policy educates staff and students with regards to being a part of a digital community and provides social media guidelines and lesson plan support for digital citizenship [8], [9], [12] - [16]

- Technology Initiatives. Technology initiatives such as wireless infrastructure were introduced, along with the loosening of rules around access to the internet and technology resources. Additionally, the introduction of various types of devices in the school board [8] - [16]

- Bring Your Own Device (BYOD). The board started encouraging teachers to open their classrooms to student devices, while purchasing various devices at school level to augment technology for students who did not have or choose not to bring their own devices [8] - [16]

- Mind shift. There was a lot of work, not necessarily in framed and defined programs or projects but rather as an overall strategy to change the culture and mind shift inside the school board to facilitate change. Adoption of the SAMR Model was one of the key undertakings to help with the organizational mind shift [8]- [16]

- Social Network. The board engaged in an online, social network based peer network which became a platform for motivation and exchange of ideas between peers [8], [10], [13], [15].

What was interesting about this huge transformation that the board undertook, was that its execution was approached differently than in the past. Almost all interviewees commented on the fact that the board had previously executed very much top down and this time around, all senior leaders were committed to avoid this type of change execution. For the most part, interviewees referenced a grass roots movement which was capitalized on by the board in order to allow those who were taking risks and changing education in their classrooms to become examples to all [8] [16]. The board also created a series of Steering Committees. Participation on the committees was voluntary and open to all. Moreover, committees became open throughout the whole process so anyone could join at any time. From a couple of major committees, sub committees were formed which displayed the board's practice of distributed leadership. Sub committees were created to work on particular projects named above and the overarching steering committee made large strategic decisions [8] - [16]. The membership of these committees was very mixed, including resource 
teachers, key teachers in the system who were already championing some of the ideas that were just being planted, Principals, Vice Principals and various managerial staff from the central offices.

Overall, the steering committee decided to choose a grassroots implementation type. They wanted to identify and enable a champion at each school who was already trying and was willing to experiment with some of the change required as part of this large transformation goal. The risk with this approach, however, was that champions were selfidentified. This was risky because the particular staff member may not be the most successful because of his /her relationships with others at the school. Some teachers could be practicing an exemplary shift in their teaching techniques but their interaction and dynamic with the other staff may not place them as ideal persons of influence. There was need for a strategic cooperation between the superintendents and the school principals to identify who the champions most likely to impact the school culture would be. In addition to enabling the school based champions, the technical (IT) resource teacher model was relied upon to further the knowledge and motivation in the system towards this change [8], [13] - [15]. Another school board in the same region also chose grassroots implementation, but their strategy was to identify the most respected person among their staff (rather than the greatest technology enthusiast). This person was then sent on training and brought the knowledge back to the school [8].

Almost all interviewees were in unison regarding creating a culture of Yes [8] - [16]. The strategy agreed upon was to try different technologies and methods and not to be restrictive or dictate what teachers should be trying in their classrooms. Before long, the work began to pick up momentum. I heard that technology was already spreading on its own because it has a natural appeal to students and creates a natural engagement in the classroom [12] [14]. A lot of teachers were already turning to this way of teaching and the board focused on enabling them to experiment and take risks.

In the interviews, leaders described that the system is continually evolving [12] - [15]. Ideas are emerging from teachers and the natural flow of adoption as the word spreads is taking place. Leadership is focused on enabling, encouraging risks and keeping the social media network strong to keep everyone connected and motivated [8], [13]. As certain experiments are tried (ex. flipped classroom), if leaders see a large adoption then they focus on the more traditional approach of formalizing that particular technique as a teaching practice, looking into policy implications, technical support and really managing the technique from an integration perspective [8]. The interviewees also provided an interesting perspective into their strategy. They realized that their change does not have an end goal but rather that they were creating a culture of change. They realized that in today's world, things will never be as stagnant and stable as in the past [9], [12], [14] - [15].

In all of the interviews, success factors emerged quickly and clearly in the conversation that led up to the interview questions. Some of these factors were already captured in this chapter describing the board's journey in educational change. These include the use of steering committees and therefore distributed leadership or influencing of the school culture.

The next sections describe interviewees' narrative on the success factors that emerged in the U.S based study by Levin and Schrum.

\section{Data Analysis}

\subsection{On Vision}

In this particular board, although they officially did have a technology and a $21^{\text {st }}$ century learning and teaching vision in place, the senior leadership did not describe it as a vision with an end goal. The senior leadership described it as a path or a direction. They all knew which direction they were headed but refused to define it, purposely. The vision itself was not very technical or defined in nature. It clearly set the tone of where education in this board is headed. In other words, the vision existed at a very high level. Students were to be the curators and creators of knowledge [12]- [15]. But how?

The board purposely avoided defining and measuring and 'boxing' it, in order to enable it to reach its full potential and creativity through grassroots, bottom up movement that was emerging from its teachers [14] - [15]. Interviewees discussed that normally leadership spends about 70 percent of the time discussing ideas and only about 30 percent of time doing them [11]. The leadership at this board agreed to commit to 10 percent of time for talking about the concepts and 90 percent of time to doing it [13] - [15]. In addition, the leadership group was encouraged to model, rather than just talk about the changes [13] - [15]. They knew that in order to ask their teachers to change, they needed to model that change first. They needed to feel the pain of learning and adoption of new concepts and breaking of their own habits.

\subsection{On Distributed leadership}

The interviewees conveyed a strong belief and practice of distributed leadership in their school system. They realized that a lack of engagement and inclusion of various participants in opportunities to lead and champion components of change will not lead to successful realization of organizational goals. 
Interviewees [8] - [15] explained that distributed leadership also gave them a tool for engaging participants to buy into the vision. This particular board established a distributed leadership culture through their use and reliance on steering committees for any large undertakings.

Within the committees, members are assigned roles based on strength and ability to make progress. What is interesting is that the use of steering committees and encouraging various people to hold positions of leadership on various opportunities permeates through the organization from the central head office to all schools. Schools are run in the same manner. The Director's Office and its coordinating Superintendents of Education run in the same manner. "It is how we get work done", I heard [9].

Was it as easy as it sounded? Delegating the responsibility is one challenging area but the various groups of people need to be collaborating as well. The challenge with the model, I heard, is that distributed leadership still relies on relationships. Allowing people into positions of power and leadership over various components, really requires the knowledge of that particular person and their dynamics with the team they are working with [13][14]. Choosing the right person to spearhead a part of your goal entails a very strategic appointment to that role, with the consideration of all personalities on that core team and their ability to make a wider scope impact in the system [12]- [14]. Just as with the discussion on vision, I heard about a level of complexity that is so core to the success of the concept of distributed leadership, but one that is not usually described in research.

\subsection{On School Culture}

"School culture is a chicken and egg thing" [10]. School culture is different in each school. There are school cultures that are severely or highly impacted by a principal. We have had principals who have visibly changed cultures every time they moved to a school. You can have an administrator who does not trust staff or one that really is interested in what they have to say.

\subsection{On Professional Development}

What this board decided to do is to work directly with the champions of change. The teachers who were already leaders in technology adoption were supported in their journey [8], [12] - [15]. Superintendents were watching what these teachers were doing and allowing them ways to experiment by providing access to technology, conferences, speakers and resources.

Professional Development became very organic in the organization. A sub-committee of the Steering Committee for the entire program was tasked with the learning and teaching agenda. The subcommittee felt it was most appropriate to make sessions available and have teachers sign up to what sparked their interest [8], [54].

Some of the characteristics of professional development in this board were described as:

- Teachers teaching their colleagues (targeted at the teachers who are technology shy and therefore would not sign up for a technology conference [8]

- One on one or self -directed options for the technology shy [8], [11], [14]- [15]

- Self-directed learning shared in a collaborative fashion [8], [13]

- Multi-tiered approach and multiple entry points for the different stages of learning [8]

- PD is not something that is done to you, it is something to engage in [13]

- Most of the learning is through one's online network. Teachers are showed how to connect with people who are learning the same things and every day spend some time educating in the network [8], [13]-[15]

- "Un-conference" - the board established conferences where participants sign up for topics of interest and join sessions to further explore that topic [8], [12] - [15]

- "Choose your own adventure" Professional Development. Schools put together a carousel of offerings. Staff were surveyed for topics of interest. Administration with school committee chooses 8-10 top choices. Staff members who developed competency in the particular areas do the leading and learning. It is important to note that the teachers chosen to lead the PD may not be experts in the competency but are engaged and on the journey to mastering the competency [13], [15].

The future is in building the culture where teachers are learning from each other [14]. Collaborative inquiry and co-learning stance are descriptions I heard from all of this study's participants. The emphasis on the future of Professional Development surely relies on collaboration and therefore relationships. Once again, the importance of not only school but organizational culture is emphasized. Creating comfort, creating a good comfortable, safe space is where the board is placing its energy when it comes to Professional Development [13].

The other important message with regards to Professional Development is that it is not to be centered on the technology. "Always start with the curriculum", "Pedagogy at the center" is what I heard from Interviewee 4 [11]. Participants described when the board provided its staff cell phones. Upon receipt of the new phone, staff signed 
a form and received no training. Technology can be learned once it is in your hands. The bigger emphasis on learning is for teachers to understand how and why education is evolving and how the pedagogy is impacted, rather than how to use a particular piece of technology [14]. Professional development must be designed in a way that models what the expectation is. Leadership for the board realized they cannot put teachers in rows and do what they trying to get away from as a learning format.

6.4.1. Social Network. A large part of the board's strategy to establish a culture of change and a part of its Professional Development strategy has been their social media network. This board was successful in establishing, very early on in this journey, a social media network which has been very active and growing since it was started [8], [13], [15]. Teachers exchange ideas, comment on each other's ideas and moments from the classrooms. Various speakers and leaders in the educational change movement have been part of the board's strategy and have become a part of the social media network as well [8], [13], [15]. Web sites such as Twitter are used for professional development and general exchange of ideas between teachers. These tools allow for an ongoing engagement and progress in learning. They keep people engaged over long periods of time. They build unison and comradery and widen social networks within the outside the organization [8].

\subsection{On Technology Planning and Technology Infrastructure}

A dependency on a reliable technology infrastructure lies at the foundation of this whole educational movement. This particular board recognized early on that in order to commence their journey, they will be relying on a level of technology that needs to be the same in all the schools. As such, the school board dug into their reserves and heavily invested in their technology platform, even prior to the beginning of their work on changing the system.

Some basic infrastructure, such as having wireless capabilities in all schools in order to experiment with various devices was given priority [8], [11] - [12], [14]. Next, the board relaxed its hardware recommendations and allowed schools to choose the technology they found best suited for each school. The board ensured to relax rules around internet access as well. Essentially, schools were provided a technology platform which enabled them to experiment with various types of technology and techniques [11], [14]. To allow these changes, numerous staff needed to rethink the way business had been done for years. Technology staff had to become extremely flexible and non-prescriptive.
Technology staff no longer had the luxury of setting rules most effective for the management of technology but rather, the goal was to provide utmost flexibility for teachers and the ability for teachers to try whatever they wanted without any restrictions. Technology staff had to begin to support multiple platforms and devices [11].

Due to the demands of changes in the system, to accommodate an upgraded technology infrastructure and a wider offering of hardware and platform types to classrooms, technology staff has been evolving to keep up with the new demands. The ideal technology support was defined by participants as:

- Completely integrated with education [8]

- Delivered by technology staff who are open to collaborate with the educator teams. Cross collaboration is key [8], [10]

- Network stability is crucial [8] - [16]

- Communication as to why technology is not working is also crucial. This goes back to (organizational) culture and respectful relationships; respect people's time in the classroom if things are not working [9].

\subsection{On Curriculum and Instructional practices}

"Pedagogy is at the center of what we do. Ultimately curriculum is at the heart of it. It's going to dictate where we are going. Far more important. It's the catalyst ...it's the buy in for the teachers...it's the epicenter. It's our core business. Change management is the difficult part technology is the easy part" [11].

This board invested significant funds toward their technology resource teacher model. Numerous technology resource teachers were hired to support classroom teachers throughout the system with their journeys towards technology adoption and the evolution of education. These resource teachers were relied upon to build the connections between technology and curriculum. In other words, the true task was to move teachers from substitution towards $\mathrm{R}$ in the SAMR model [10].

Part of the technology resource teachers' directive was to boost staff morale and help them understand how the technology is making an impact. In other words, it is to help move teachers toward understanding and buying into the reason for the changes to the way they teach. Helping staff understand they have a key role in the success of students is a huge task [10].

In addition to the resource teacher model, the board heavily relied on modeling what they wanted to accomplish in the classroom. Various levels of leadership were modelling, even by changing simple things like carrying a book or iPad to meetings [14] - [15]. Notebooks and pens were replaced by technology. Meeting and presentation formats were 
changed. Leadership got involved in social media platforms [8], [13] - [15]. Leadership gave schools and teachers permission to experiment on their own as well.

\subsection{On Funding}

Funding has become a major player when it comes to success factors for technology implementations. Technology implementations are necessarily tied to cost as new technology always involves a cost. The evolution of education is dependent on technology infrastructure and resources for teachers and students.

Although many school boards are hopeful that BYOD (Bring Your Own Device) programs will alleviate some of the cost issues for school boards, the strategy is quite long as most school boards still struggle to ensure an adequate technology infrastructure is in place in schools.

When it comes to funding, there are many areas outside of technology that require funding. Professional Development is a very important factor during times of change and can also be a very costly one. In addition, there is the development of communication materials, translation of letters for parent communications and other items that tie back to an increased demand for funding in order to support major change execution [8].

Another area creating a demand for funding is the evolution of classroom set up, maker spaces, learning spaces, learning commons etc. As areas of the school are evolving to accommodate the new learning style, the funding demands grow with them [9]. However, other interviewees [11], [14] - [15] highlighted that as they visited with various school boards, they found that there are school boards with fewer resources that have often been very successful with their technology adoption. Funding is not the primary condition of success.

\subsection{On Partnerships}

There was a visible difference between the American versus Canadian reliance on partnerships in education. Interviewees in this research emphasized the need to form internal partnerships more so than the external partnerships defined in U.S based research.

Some interviewees even acknowledged the geographical difference on this subject. Partnerships are not as heavily relied upon in Canada [8], [13]. In fact, the partners identified as critical during this time of change were the board's trustees. Trustees need to help the board to access funds and amend policies as required to support the systemic goals they are working on changing [12].

Trustees need to be 'brave' as they are accountable to the public. In the case of wireless technology implementations, trustees received a lot of community revolt at firsts, as the idea of Wi-Fi in schools seemed threatening to parents [9].

The other partnership identified was with technology vendors. There was some discussion by the interviewees that indicated there are opportunities to form better partnerships with technology vendors which can be leveraged in schools towards better integration of the technology through trainings support or volume discounts. Interviewees definitely did not feel that paying full value for a device by the board and by parents was the most opportunistic deal for education [9], [10], [12], [14], [15].

In general, interviewees were split on the idea of schools doing more with corporate partners. Some felt that since parents and students spend money with organizations such as fast food restaurants, then why not capitalize on fast food restaurants contributing back to the community by allowing contribution to the school? [9], [15]. Others felt that to rely on a business for contributions may take the freedom of choice away from education down the road [8], [10]. Also, there is a concern about working with organizations that exemplify the values being taught by the board [9]. For example, development of healthy lifestyles and how this ties in with sponsorship by a soda company. Perhaps association with a less than prime nutrition choice type of product is not a most ideal partnership for a school board. Interviewees discussed partnerships with other organizations which provide opportunities for our students. This included partnerships with Universities who provide space for our students for weekend classes and extra opportunities for engagement and learning [13], [15].

\section{Success Factors according to interviewees}

Each of the interviewees, was initially asked for their "absolute must have" success factors for technology implementations in schools. The following list is a summary of factors discussed by this particular group of educational leaders. A further discussion of these factors follows. The factors were organized into categories by the researcher.

\subsection{Culture}

- Championed by well-respected colleague [8]

- Culture of Yes - instead of thinking of reasons why it will not work, think of why it will. Also, allowing staff to take risks and experiment with technology and ideas [9], [13]

- Teachers who are innovators. Not afraid to take risks but also willing to listen [10]

- Co learning stance. Everyone is in this together; teacher, principal, superintendent, technical staff, resource teachers [12], [13], [15] 
- $\quad$ Letting people make mistakes [12], [15]

- Flattening of hierarchies - everyone in the organization innovates [8], [12], [13], [15]

- You cannot dip your toe in it. You have to realize you are going to be submersed [14]

- Honor the knowledge and expertise your staff come in with [13]

- Create the conditions to facilitate the movement of your staff [14]

- Model the behavior, enable the technology, facilitate [14], [15].

\subsection{Leadership}

- Administrators who are champions of technology through modelling and supporting their teachers. Willing to listen to teachers [10]

- Do not allow it to be just one staff members who decides what to do [10]

- Vision of the administrator to be articulated [10]

- Collaborative effort - having a teacher lead the pact, having the teacher reach out for ideas and support resources [10].

\subsection{Technology}

- Technology that does not fail [8] - [15]

- Availability of online resources [8]

- Wireless infrastructure [8]- [15]

- Platform agnostic. The fact that we had to say we are going to be open to all platforms [12]

- Technology department open to change rules and management of technology to accommodate curriculum first [13].

\subsection{Professional Development}

- Multiple entry points - if you're a novice, you must logon and have novice tools. If you're more advanced, offer more advanced [8]

- Support and training for the teachers is most important [11].

\subsection{Curriculum and Instructional Practice}

- SAMR ladder: must move up the model. Cannot do substitution forever [9], [12], [15]

- Pedagogy: teachers willing to take risks. Being resilient and adaptable [9], [16]

- Rethinking of higher order thinking tools such as critical thinking skills. Engaging the world in problem solving. Having social conscience and developing morality and values [14].

\subsection{Partnerships}

- Partnerships between technology vendors, technology department and the resource teachers should be very collaborative to allow for the best options of technology in the classrooms [9], [11] - [15].

\section{Emerging themes summary}

The themes that emerged in these interviews were less about the factors required for technology change but more about creating a culture of change. This leadership placed its energy in creating the underlying understanding, sparking passion and conveying the urgency for educational change. The belief is that once teachers understand the need to change in order to equip students with skills they will need in their world, not our world, teachers will find creative ways to evolve their teaching practice. This is a little counter intuitive to how organizations have executed their goals in the past. Usually, long terms goals are only clearly known by senior leadership in organizations. Senior leadership, in turn, breaks up the goals into numerous initiatives which become very scripted and prescribed in nature. This is the old style, top down approach. This board chose a different strategy. Long term goals and vision are shared and the importance of their understanding by teachers is very important to leadership. The actual ways to get to the goals are not prescribed, but rather, basic environment, infrastructure and culture essentials are prepared to create a change conducive environment. From there, it is up to the teachers to innovate and try what works best. Teachers are trusted, as professionals, to evolve their practices with best intentions for the students.

The philosophies and practices of successful technology implementations in the K-12 context which emerged in this particular school board's journey are:

\section{- Grass Roots Movement}

- Understanding the goal

- Open to experimentation

- Continuous, long term emphasis

- Modelling what you preach

- Genuine passion for education

These philosophies and practices are listed here due to their frequency of mention by the interviewees.

\subsection{Grass Roots Movement}

Emphasis on a grass roots movement. This board realized the importance of capitalizing on the teachers who were already the technology leaders in their schools. Providing these teachers with the attention, spotlight and equipping them with the tools they could creatively explore was key in gaining attention from others and creating a genuine interest in the system. 


\subsection{Understanding the goal}

Rather than framing the journey of change as a journey with a definite start and finish and a prescribed, defined end goal, this board emphasized the importance of understanding why this change is important. The change in education toward the adoption of learning and teaching styles, with the tools of technology in the classroom, is likely a change that will keep evolving. Education may never have the luxury of being as stable and steady as it has been in the past few decades. The result of this stagnancy has been clearly proven by various studies illustrating a decrease in student engagement. "The research on brain activity by Rosalind Picard and her colleagues at MIT's Media Lab suggests that students' brain activity is nearly non-existent during lectures - even lower than when they are asleep" [5].

\subsection{Open to experimenting}

Taking risks in the classrooms was encouraged for the sake of finding out what works best to engage students and stage learning opportunities to expand problem solving skills and encourage enquiry.

\subsection{Continuous, long term}

"Large-scale changes cannot be considered successfully implemented unless they are able to survive evolution of the system and remain useful in a changing world." [3].

This change in education was presented to the entire system as a continuous, long term and evolving change. This led the board to focus on the goal of providing students with a classroom experience which encouraged enquiry and problem solving skills.

\subsection{Modelling}

Modelling became very important. In words of the interviewees, you cannot expect people to move if you are not willing to make changes yourself. The board's leadership took the first step towards changing by adopting technology into the ways they do everyday things. They modelled by participating in the social media dialogue. They learned, they shared and they remained engaged throughout the whole process.

\subsection{Genuine passion for education}

The most powerful factor that became visible to me very early on in the interviews was the genuine passion for education on behalf of the interviewees. One of the interviewees went as far as admitting he is afraid that in his career he will not be able to take part and influence the full extent of the much needed education shift [13].

\section{Conclusions}

The practices and philosophies that emerged in the Levin and Schrum study in the United States, and the additional layer of change factors discovered in this research by examining the experiences of a large school board are confirmed in various literatures.

The OECD (Organization for Economic Cooperation and Development) published work entitled "Schools for 21 $1^{\text {st }}$-Century Learners" in 2015. Andreas Schleicher, the author of this work discusses themes such as:

- Distributed Leadership

- Professional Development

- Instructional Leadership (curriculum and instruction)

- Collaborative Planning Environments [46].

The Equinox Blueprint, a report published in April 2014 builds on a series of professional conferences on the subject of "Learning 2030". It discusses changes required to propel education change for the students born today who will be graduating in 2030. This extensive report discusses the need to switch to project based learning in the classroom, the need for teachers to evolve as learning coaches, the need to start changing learning environments (classroom spaces, class sizes and age groupings of students), the need to revisit how students are evaluated and the need to give schools the ability to make their own decisions and have autonomy over their management in order to foster creativity. The report discusses the secrets to scaling such a large implementation:

Local input - the author refers to schools' ability to mold their own reforms. This is consistent with this paper's account of this school board's emphasis on grass roots movement rather than a top down approach.

Global applicability through inclusive reforms Schleicher emphasizes that the scope of this large change needs to be driven by a goal to "improve outcomes for all students" [46]. This theme was also echoed in the interviews with this board's superintendents who stressed the importance of always originating the vision and all the outcomes of this change on the students these changes are meant for.

Sustainability through support networks Schleicher discusses the need for large scale reform networks which will ensure sustainability of these changes. In the case of this board, we discussed 
above the successfully established and active social media network and the interviewees strong emphasis on collaboration and internal and external partnerships.

Pathway to change - Schleicher also discusses an entire pathway to change which is comprised of:

- creating an urgency, or, in other words, ensuring the understanding of what is a stake for students if they miss out on gaining the important skills they need to be equipped with for a world of tomorrow

- creating a coalition - assembling people of influence from various areas of the organization

- creating a vision - a vision around which to create a strategy

- communicating the vision - having the vision is not enough!

- remove obstacles - identifying change leaders who will make changes possible

- Create short-term wins - the coalition will map out the strategy which includes achievable targets that can be celebrated [46].

Although not termed in the same way, the concepts revealed by the board have since then shown up in most recent literature published on best practices for technology based education changes.

Another significant release in latest research on the subject of change in large school systems is a case study report by the Canadian Education Association (CEA). Entited "Ottawa Catholic School Board: Leading and learning for innovation. A framework for district-wide change", the study analyzes this school board's blueprint for change. The study discusses many stakeholders involved in a system change, including students, teachers and trustees. We learn about the importance of a collaborative work when discussing system changes. This is a theme that validates the importance of distributed leadership. The Canadian Education Association also draws attention to the entire planning process and the importance of constant observation during plan execution. This is something that has not come up in previous research, but once the various techniques are established, there needs to be a constant assessment of the change and correction. In formal Change Management methodologies such as Prosci's ADKAR, assessment along the way and resistance planning are methods used when executing change. Overall, the CEA really focuses on the communications and relationships components in a change management plan which validate so many concepts that emerged in research to date, mentioned throughout this paper.

I hope that the findings in this study enable others, who are facing the challenge of creating change in large organizations, to look at change through a different lens or perspective. Are you trying to create change but you are still stuck in your usual ways of doing things? Are you willing to change first? Are you truly leading the change by creating enough understanding to gain the required support? Are you rewarding your champions? Are you placing your energy and emphasis on the leaders or the nay-sayers?

I hope this paper helps you with taking a critical look at your approach and evolve towards a more mature, inclusive model for creating change.

\section{References}

[1] Angeli, C., \& Valanides, N. (2009). Epistemological and methodological issues for the conceptualization, development, and assessment of ICT-TPCK: Advances in technological pedagogical content knowledge (TPCK). Computers \& Education, 52(1), 154-168. doi: 10.1016/j.compedu.2008.07.006.

[2] Beer, M. (2014). Comments on "Effects of change interventions: What kind of evidence do we really have?". The Journal of Applied Behavioral Science, 50(1), 28-33. doi:10.1177/0021886313515610.

[3] Brooks Michael and Holmes Bob. Equinox Blueprint Waterloo Global Science Initiative 2014. [Online] Available:https://www.edu.gov.on.ca/eng/literacynumerac y/inspire/research/CBS_PrincipalsCoLearners.pdf.

[Accessed August 15, 2015].

[4] Fullan, Michael. "Great to Excellent: Launching the Next Stage of Ontario's Education Agenda". 2013. [Online]. Available: http://www.michaelfullan.ca [Accessed July 07, 2015].

[5] Fullan, Michael and Langworthy, Maria. "A Rich Seam. How New Pedagogies Find Deep Learning". Pearson. 2014.

[6] Fritz, Jane. Systems Theory Overview. [Online]. Retrieved from http://www.cs.unb.ca/profs/fritz/ cs3503/system35.htm. [Accessed on July 23, 2014].

[7] Gormly, E. (1996). Implementation of technology in American public schools: a qualitative study. American Secondary Education, 24(2), 14-25.

[8] Interviewee 1, Communications Manager. (June 2015). Personal Interview.

[9] Interviewee 2, Superintendent of Education. (June 2015). Personal Interview.

[10] Interviewee 3, Instructional Teaching Coordinator. (June 2015). Personal Interview.

[11] Interviewee 4, IT Manager. (May 2015). Personal Interview.

[12] Interviewee 5, Superintendent of Education and Curriculum and Instruction Department Head Interview. (June 2015). Personal Interview. 
[13] Interviewee 6, School Support Officer and Principal (June 2015). Personal Interview.

[14] Interviewee 7, Superintendent of Education. (June 2015). Personal Interview.

[15] Interviewee 8, Superintendent of Education. (June 2015). Personal Interview.

[16] Interviewee 9, IT Manager. (June 2015). Personal Interview.

[17] Kopcha, T. (2010). A systems-based approach to technology integration using mentoring and communities of practice. Educational Technology Research and Development, 58(2), 175-190. doi:10.1007/s11423-0089095-4.

[18] Levin, B. B., \& Schrum, L. (2013). Using systems thinking to leverage technology for school improvement: Lessons learned from award-winning secondary Schools/Districts. Journal of Research on Technology in Education, 46(1), 29-51. Retrieved from http://search.proquest.com/docview/1492734491?accounti $d=14771$. [Accessed June 2015].

[19] Liu, Y., \& Szabo, Z. (2009). Teachers' attitudes toward technology integration in schools: A four-year study. Teachers and Teaching: Theory and Practice, 15(1), 5-23. doi:10.1080/13540600802661295.

[20] Nyoni, J. (2012). A 21st century collaborative policy development and implementation approach: A discourse analysis. Africa Education Review, 9(2), 289-307. doi:10.1080/18146627.2012.721607

[21] SAMR Model Diagram. [Online]. Retrieved from: http://www.schrockguide.net/uploads/3/9/2/2/392267/580 5548.jpg. [Accessed July 2015].

[22] Scanlon, E., \& Issroff, K. (2005). Activity theory and higher education: Evaluating learning technologies. Journal of Computer Assisted Learning, 21(6), 430-439. doi:10.1111/j.1365-2729.2005. 00153.x.

[23] Canadian Education Association (CEA). Case Study Report: Ottawa Catholic School Board. Leading and learning for innovation. A framework for district-wide change. May 2016. 